International Journal of Agriculture, Environment and Bioresearch

Vol. 4, No. 03; 2019

ISSN: $2456-8643$

\title{
EFFECTS OF SOYBEAN MEAL ON NEW MUSCLE GENERATION AND GROWTH OF SILVER BARB, BARBONYMUS GONIONOTUS
}

\author{
Halima Jahan, Mst. Arzu Parvin, Rabeya Akter and Zakir Hossain* \\ Department of Fisheries Biology and Genetics Bangladesh Agricultural University, Mymensingh-2202, Bangladesh
}

http://doi.org/10.35410/IJAEB.2019.102110

\begin{abstract}
The aim of this study was to evaluate the effects of substituting fishmeal (FM) with soybean meal (SM) on new muscle generation of silver barb, Barbonymus gonionotus. Five diets were prepared with SM 0 (FM 100), SM 25 (FM 75), SM 50 (FM50), SM 75 (FM25) and SM 100\% (FM 0\%) by replacing FM with SM. Each diet was fed to B. gonionotus having initial weight of $8.80 \pm 3.11 \mathrm{~g}$ to apparent satiation twice a day for six months. During the 120th days, the growth were significantly $(\mathrm{P}<0.05)$ higher in fish fed with SM50 diets compared to SM0 diets. But in 150th days, growth were significantly $(\mathrm{P}<0.01)$ higher in fish fed with SM25 diets compared to SM0 diets. Finally during 180th days, growth were significantly $(\mathrm{P}<0.1)$ higher in fish fed with SM50 and SM25 diets compared to SM100 diets. There was a significantly $(\mathrm{P}<0.05)$ increased number of muscle fiber atSM50, SM25 and SM0 diets compared to SM100. Diameter of muscle fiber $(\mu \mathrm{m})$ was significantly $(\mathrm{P}<0.01)$ increased at SM50, SM25 and SM0 diets compared to SM100 diet. The results of the present study indicated that substitution of upto50\% SM with FM enhanced the muscle growth by promoting hyperplasia and hypertrophy in B. gonionotus.
\end{abstract}

Keywords: Muscle fiber, Diets, Protein source, Hyperplasia, Hypertrophy

\section{INTRODUCTION}

Bangladesh is considered one of the most suitable countries in the world for freshwater aquaculture. Success in aquaculture depends primarily on the use of quality fish feed. Reducing the level of fishmeal (FM) in fish diets is a major challenge for intensive aquaculture. Potential substitutes should match both the high protein needs of fish and their indispensable amino acid requirements. Several trials have been conducted with different aquaculture species in order to find plant ingredients or combinations of different plant ingredients that might replace FM. It is now well established that FM can be partially substituted by alternative protein sources but the success of total substitution of FM without growth impairment has been very limited (Kaushik et al., 1995; Rodehutscord et al., 1995; Watanabe et al., 1998).

Muscle growth mechanisms in teleosts such as salmonids that reach a large adult body size differ from those occurring in other animals such as mammals and birds. Indeed, muscle enlargement in fish occurs both by hypertrophy (i.e., increase in size of existing muscle fibres) and by hyperplasia (i.e., recruitment of new muscle fibres) not only before hatching but also during a large part of post-hatching life (Rowlerson and Veggetti, 2001). In most teleosts axial skeletal muscle mass represents more than $60 \%$ of body mass. These muscles consist mainly of deep fast 


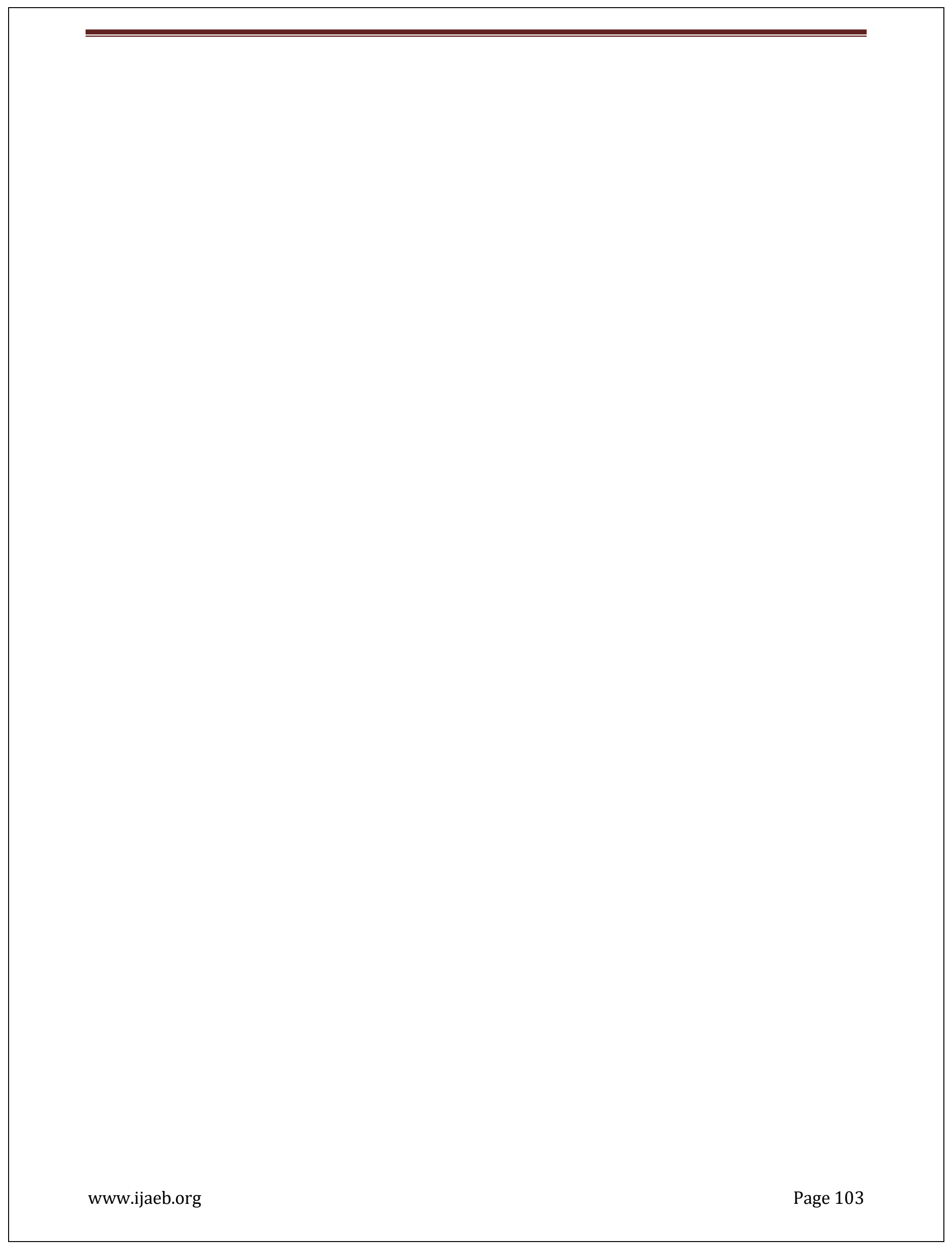


white fibres (up to 90\%), covered by a thin superficial layer of slow red muscle fibres located under the skin, and a layer of intermediate (pink) fibres between them. Changes in the somatic growth of fish are thus mainly attributable to changes in total white muscle growth, which are themselves due to variations in muscle hypertrophy and/or hyperplasia. Changes in the relative contributions of hyperplasia and hypertrophy to muscle growth lead to changes in muscle cellularity (i.e., in the distribution of muscle fibre size). It has been shown that in the white muscle of fish juveniles such changes in muscle cellularity are linked to changes in environmental factors such as rearing temperature (Weatherley et al., 1979, 1980b),incubation temperature (Johnston et al., 2000; Alami-Durante et al., 2007), photoperiod (Johnston et al., 2003) and seasonal variations in temperature (Alami-Durante et al., 2007). Modifications of white muscle cellularity also occur in juvenile fish with changes in plane of nutrition (Weatherley et al., 1979, 1980b; Kiessling et al., 1991) and changes in dietary protein level (Johnston et al., 2002; Bjornevik et al., 2003; Silva et al., 2009) or lipid source (Fauconneau et al., 1997). The study was designed to evaluate the effects of increasing levels of substitution of FM meal by soybean meal (SM) sources on skeletal new muscle generation.

\section{MATERIALS AND METHODS}

\section{Experimental design}

For the study of the effect of replacement of FM with SM on B.gonionotus, ten cisterns $\left(2.44 \times 1.23 \times 0.46 \mathrm{~m}^{3}\right)$ were used in Mini Hatchery Complex of Department of Fisheries Biology and Genetics, Bangladesh Agricultural University, Mymensingh, Bangladesh. Eight cisterns corresponded to experimental treatment and two cisterns used for control. Each cistern was stocked with 60 fingerlings of $B$. gonionotus having initial weight and length $8.80 \pm 3.10 \mathrm{gm}$ and $8.62 \pm 0.90 \mathrm{~cm}$, respectively and maintained for six months. For treatment SM100 (FM0), SM75 (FM25), SM50 (FM50), SM25 (FM75) and for control SM0\% (FM100\%) were used as a source of protein (Table 1).

Table 1. Composition of experimental feed ingredients. 


\begin{tabular}{|lccccc|}
\hline Ingredients & \multicolumn{5}{c|}{ Percentage (\%) } \\
\cline { 2 - 6 } & 100 SM & 75 SM & $\mathbf{5 0 ~ S M ~}$ & 25 SM & 0 SM \\
\hline Wheat flour & 20 & 20 & 20 & 20 & 20 \\
Wheat Bran & 30 & 30 & 30 & 30 & 30 \\
Rice Bran & 40 & 40 & 40 & 40 & 40 \\
Maize Meal & 27 & 27 & 27 & 27 & 27 \\
Fish Meal & 0 & 20 & 40 & 60 & 80 \\
Soybean Meal & 80 & 60 & 40 & 20 & 0 \\
Vitamin-B & 1 & 1 & 1 & 1 & 1 \\
Cod Liver Oil & 2 & 2 & 2 & 2 & 2 \\
\hline
\end{tabular}

\section{Feed formulation and analysis of feed}

Feed containing SM0 (FM100), SM25 (FM75), SM50 (FM50), SM75 (FM25) and SM100\% (FM0\%) were prepared using rice bran, wheat flour, FM, maize meal, SM, vit-B complex and cod liver oil as ingredients. Required amount of ingredients were ground finely by a grinding machine and sieved with fine mesh net. After sieving, required amount of each ingredient was weighed as per formulae using AND-GULL precision electric balance (Mode-E600 Dual, made in UAE). The proximate composition of experimental ingredients and feeds are shown in Table 2 and Table 3. After mixing all the ingredients, exact amount of water was added. Then feeds were formulated as balls manually. The diets were allowed to store in the plastic bag in air tight condition and kept in refrigerator for later use. Analyses of moisture, crude protein, crude lipid and ash contents of the dietary ingredients and feeds were performed by the standard procedures (AOAC, 1980). Moisture was determined by drying the samples in an oven at $105^{\circ} \mathrm{C}$ to constant weight; crude protein was analyzed by the Kjeldahl method $(\mathrm{N} \times 6.25)$ with a FOSSKjeltec 8400 analyzer (Tecator, Höganäs, Sweden) after acid digestion in an auto-digester (FOSS; Tecator); crude lipid was determined by Soxhlet extraction in ether; ash content was measured by the combustion method in a muffle furnace at $550{ }^{\circ} \mathrm{C}$ for $8 \mathrm{~h}$.

\section{Experimental fish and feeding trial}

The required number of B. gonionotus was collected from Deshbondhu Hatchery, Shomvugonj, Mymensingh, Bangladesh. Fish were conditioned for about 7 days. Then healthy, strong and more or less equal sized fishes were used for experiment. Fishes were randomly divided into each treatment group. The fish were fed twice daily in the morning (9:00 AM) and afternoon (5:00 PM). Feeds were supplied near the shelter made for the fish. The unused food stuff, debris and feces were removed by siphoning method on a daily basis. The whole cistern was emptied, cleaned and washed with potassium permanganate every 30 days interval to minimize the fouling 
from the provided feeds and metabolic wastes while $20 \%$ of cistern water was exchanged every day through the inlet and outlet system. Periodic sampling was done to assess the health condition of the fish. Sampling was done monthly for growth measurement. During sampling 10 fishes from each cistern were caught randomly with the help of scoop net by lowering the water level. Then the weight and length of each fishes were taken by 6 digit sensitive electric balance and measuring scale, respectively.

\section{Water quality parameters}

Temperature, dissolved oxygen (DO) and $\mathrm{pH}$ of water in each cistern were recorded daily. Temperature, DO and $\mathrm{pH}$ were recorded by using a Celsius thermometer, a digital DO meter (multi 340 iset, DO-5509; China) and was a portable digital pH meter (MICRO-TEMP, pH 500, Romania), respectively.

\section{Muscle sample collection}

The experimental fish muscle of each treatment group were collected by dissection and preserved in Bouin's fluid with labeled vials for further study.

\section{Determination of muscle generation}

Fixed muscle samples were dehydrated in a graded ethanol series, cleared in xylene and embedded in paraffin and analyzed according to Valente et al., (2016). Transversal sections (10 $\mu \mathrm{m}$-thickness) were cut in each block and stained with haematoxylin-eosin before being cover slipped for morphometric analysis. Measurements were obtained using interactive image J analysis system software, captured by a light microscope (BX51, Olympus, Japan). The dorsal area occupied by white muscle (muscle CSA, mm2) was computed through Image J Analyzing software, after circumscribing the physical limit of the muscle section only. Total number (N) of white muscle fibres was calculated as: NA× muscle CSA, where NA is the number of white muscle fibres per unit area (fibres $\mathrm{mm}^{-2}$ ) and muscle CSA is the total white muscle area $\left(\mathrm{mm}^{2}\right)$. The corresponding white muscle fibre diameter $(\mu \mathrm{m})$ was determined Image $\mathrm{J}$ Analyzing software. All measurements concerning white fibres used $10 \times$ magnification objectives.

\section{Statistical analysis}

All the data were analyzed by one-way analysis of variance (ANOVA) using SPSS version 17.0 software (SPSS Inc., Chicago, IL, USA). When ANOVA detected a difference among groups, Duncan's multiple range test was used to identify the significant difference in the means. Data are presented as mean \pm standard error of the mean (SE).

\section{RESULTS}

\section{Water quality parameters}

The water quality parameters such as temperature, $\mathrm{pH}$ and dissolved oxygen of cistern were $25.5 \pm 1.5^{\circ} \mathrm{C}, 7.3 \pm 0.10$ and $9.5 \pm 0.5 \mathrm{ppm}$, respectively.

\section{Proximate composition of feed ingredients and formulated feed}


The proximate compositions of the dietary ingredients were determined following the standard methods given by Association of Official Analytical Chemists (AOAC, 1980) in the Nutrition Laboratory of Faculty of Fisheries, BAU, Mymensingh. Percent moisture, ash, protein, lipid, crude fibre, and nitrogen free extract (i.e. carbohydrate) were measured during the chemical analysis. Proximate composition of the different ingredients of feed and formulated feed are shown in Table 2 and Table 3, respectively.

Table 2. Analysis of proximate composition (\%) of different dietary ingredients (Dry matter basis).

\begin{tabular}{|lcccccc|}
\hline \multicolumn{1}{|c}{ Ingredients } & Moisture & $\begin{array}{c}\text { Crude } \\
\text { Lipid }\end{array}$ & $\begin{array}{c}\text { Crude } \\
\text { Protein }\end{array}$ & Ash & $\begin{array}{c}\text { Crude } \\
\text { Fibre }\end{array}$ & Carbohydrate \\
\hline Wheat Flour & 12.51 & 2.20 & 9.22 & 1.68 & 0.80 & 73.59 \\
Rice Bran & 18.78 & 10.60 & 11.98 & 7.36 & 7.20 & 44.08 \\
Wheat Bran & 14.96 & 4.80 & 14.51 & 2.89 & 6.90 & 55.94 \\
Maize Meal & 14.33 & 3.20 & 16.08 & 7.64 & 6.70 & 52.05 \\
Soybean Meal & 14.80 & 4.28 & 41.54 & 5.54 & 6.88 & 26.96 \\
Fish Meal & 10.17 & 8.46 & 60.61 & 18.03 & 1.80 & 0.93 \\
\hline
\end{tabular}

Table 3. Analysis of proximate composition (\%) of different dietary feeds (Dry matter basis).

\begin{tabular}{|lcccccc|}
\hline \multicolumn{1}{|c}{ Feed } & Moisture & $\begin{array}{c}\text { Crude } \\
\text { Lipid }\end{array}$ & $\begin{array}{c}\text { Crude } \\
\text { Protein }\end{array}$ & Ash & $\begin{array}{c}\text { Crude } \\
\text { Fibre }\end{array}$ & Carbohydrate \\
\hline SM100 & 48.36 & 3.20 & 15.05 & 3.77 & 4.20 & 25.42 \\
SM75 & 49.62 & 3.36 & 16.04 & 5.20 & 4.48 & 21.30 \\
SM50 & 46.33 & 3.46 & 19.02 & 6.89 & 4.66 & 19.64 \\
SM25 & 44.83 & 3.88 & 19.45 & 8.11 & 5.20 & 18.54 \\
SM0 & 47.43 & 3.96 & 20.07 & 10.63 & 4.36 & 13.55 \\
\hline
\end{tabular}

Fish growth performance 
A significantly higher $(\mathrm{P}<0.05$ and $\mathrm{P}<0.1)$ body weight was observed in fish fed with the diets SM25 and SM0 compared to diet SM100 at 150 days. At the day of 180 , significantly higher body weight was also found in fish fed with the diets SM50, SM25 and SM0 compared to diet SM100 (Table 4).

Table 4. Average weight \pm SD of Barbonymus gonionotus fed with the formulated diets for 6 months at 30 days interval.

\begin{tabular}{|llllll|}
\hline Intervals & SM100 & SM75 & SM50 & SM25 & SM0 \\
\hline 0 days & $8.8 \pm 3.11$ & $8.0 \pm 2.33$ & $8.3 \pm 2.65$ & $7.9 \pm 1.34$ & $8.2 \pm 2.5$ \\
30 days & $16 \pm 2.34$ & $9.8 \pm 0.74$ & $9.0 \pm 2.34$ & $8.6 \pm 2.88$ & $10.6 \pm 1.51$ \\
60 days & $21.8 \pm 8.31$ & $12.4 \pm 2.96$ & $15.4 \pm 2.79$ & $18.4 \pm 6.87$ & $13.2 \pm 3.03$ \\
90 days & $29.4 \pm 1.67$ & $20.4 \pm 2.50$ & $28 \pm 3.16$ & $22.8 \pm 1.92$ & $23.4 \pm 1.51$ \\
120 days & $34.3 \pm 2.87$ & $28.4 \pm 2.30$ & $37 \pm 3.80$ & $32.8 \pm 1.28$ & $33.7 \pm 2.96$ \\
150 day & $38.2 \pm 3.45$ & $35.8 \pm 4.68$ & $43.6 \pm 0.84$ & $46.1 \pm 3.45^{*}$ & $56.3 \pm 1.84^{* *}$ \\
180 days & $40.4 \pm 6.73$ & $41.6 \pm 2.57$ & $52.2 \pm 1.48^{*}$ & $64.9 \pm 3.2^{* *}$ & $76.8 \pm 1.93^{* * *}$ \\
\hline
\end{tabular}

Values are presented as mean \pm SD. Values in the same raw having different superscript asterisks are significantly different $(* \mathrm{P}<0.05, * * \mathrm{P}<0.01$ and $* * * \mathrm{P}<0.001$ vs $\mathrm{SM} 100)$.

\section{Muscle generation}

Fish fed with SM50, SM25 and SM0 had significantly higher $(\mathrm{P}<0.05)$ number of white muscle fiber compared to SM100 (Table 5). The average diameter of muscle fiber $(\mu \mathrm{m})$ was significantly $(\mathrm{P}<0.01)$ increased in diet SM0, SM25 and SM50 compared to diet SM100 (Table5). Diameter of muscle fiber $(\mu \mathrm{m})$ was decreased with the increasing SM in diet (Figure $1)$.

Table 5. Muscle texture of Barbonymus gonionotus fed with the experimental diets for 6 months.

\begin{tabular}{|llllll|}
\hline Dietary treatments & SM100 & SM75 & SM50 & SM25 & SM0 \\
\hline Muscle area $\left(\mathrm{mm}^{2}\right)$ & 2640 & 2640 & 2640 & 2640 & 2640 \\
Total number of fibres & $32.66 \pm 2.51$ & $37.66 \pm 2.51$ & $38.3 \pm 2.08^{*}$ & $39.66 \pm 2.51^{*}$ & $41.66 \pm 1.5 *$ \\
Fibre diameter $(\mu \mathrm{m})$ & $63 \pm 2.52$ & $66 \pm 3.21$ & $87 \pm 7.43^{* *}$ & $77 \pm 2.73^{*}$ & $81 \pm 1.70^{* *}$ \\
\hline
\end{tabular}

$* \mathrm{P}<0.05$ vs SM100and $* * \mathrm{P}<0.05$ vs SM100 

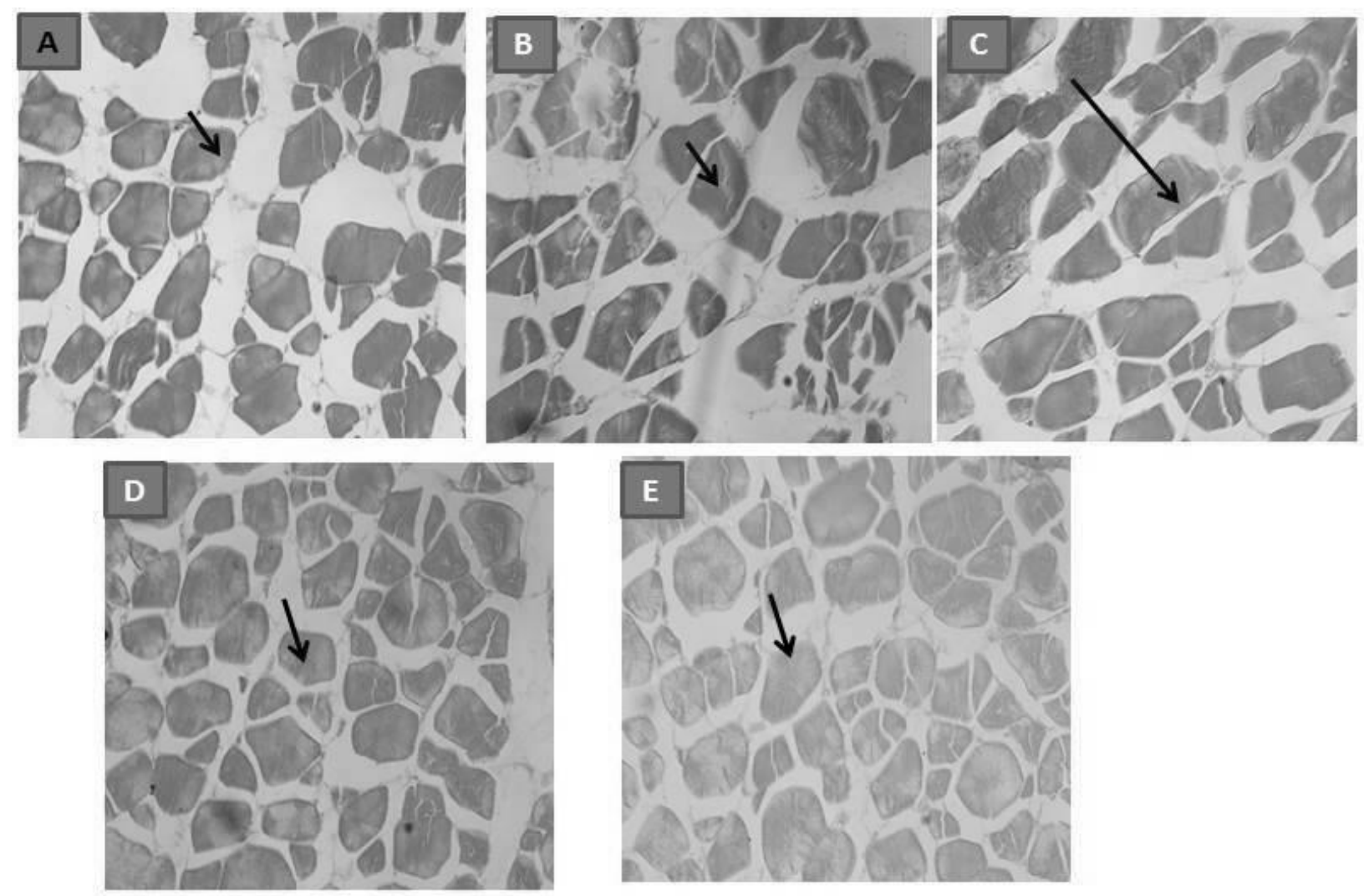

Figure 1.Cross sectional area of dorsal muscle. A, B, C, D, E indicate cross sectional area of muscle of B. gonionotus fed with diets SM100, SM75, SM50, SM25, and SM0, respectively containing $100 \%, 75 \%, 50 \%, 25 \%$ and $0 \%$ SM, respectively.

\section{DISCUSSION}

In B. gonionotus, $50 \%$ SM diet significantly $(\mathrm{P}<0.05)$ increased number of white fibre with a concomitant increase of fibre density and the diameter size of fibre. The increase in somatic growth observed in the B. gonionotus fed with 50\% SM diets was linked to significant changes in white muscle growth dynamics which resulted in a increase in the median white muscle fibre size. This finding confirms the plasticity of B. gonionotus skeletal white muscle growth dynamics which was previously shown to be affected by ration level (Weatherley et al., 1980; Kiessling et al., 1991) or by changes in nutrient supply, such as dietary lipid/fatty acid sources (Fauconneau et al., 1997). Refstie et al., (1998) determined that high levels of replacement of FM by SM leads to reduced growth in salmonids. The decrease in growth from diets where SBM replaces FM at high levels in carnivorous fish may occur due to the impact of many antinutritional factors (ANFs) present in SBM, which may prevent digestion and nutrient absorption, and therefore result in higher feed conversion ratios (Grisdale-Helland et al., 2008). These include protease inhibitors (trypsin inhibitors), oligosaccharides (stachyose, raffinose, etc.), 
saponins, isoflavones, antigens (glycinin, conglycinin, and lectins), phytate, and tannins (Refstieet al., 2006; Knudsen et al., 2007; Iwashita et al., 2009). The consequence of level of $50 \%$ substitution of FM bya mix of SM was an increase in the median diameter of white muscle fibre after 6 months of feeding, which remained significant even when corrected for length differences among groups. The changes observed in distribution of muscle fibre sizes may reflect changes in hyperplasia and/or hypertrophy. The number of muscle fiber was varied in different treatment groups. Luisa et al., (2016) determined that several muscle growth related genes by increasing levels of plant protein sources that alter muscle cellularity and textural properties of Senegalese sole when total fish meal is replaced by plant protein. In conclusion these results suggest that the replacing $50 \%$ of FM with SM significantly increased muscle fibre of $B$. gonionotus.

\section{ACKNOWLEDGEMENT}

This research was financed from the special grants funded by Ministry of Science and Technology, Government of the People's Republic of Bangladesh, Dhaka, Bangladesh.

\section{REFERENCES}

Alami-Durante H., Olive N.,Rouel, M., 2007. Early thermal history significantly affectsthe seasonal hyperplastic process occurring in the myotomal white muscle of Dicentrarchus labrax juveniles. Cell and Tissue Res. 327: 553-570.

AOAC (Association of Official Analytical Chemists). 1980. Official methods of analysis of Association of Official Analytical Chemists (ed. W. Hoewitz), $13^{\text {th }}$ edition Washington, D.C. p. 78.

Bjornevik M., Beattie, C., Hansen, T., Kiessling, A., 2003. Muscle growth in juvenile Atlantic salmon as influenced by temperature in the egg and yolk sac stages and diet protein level.

J. Fish Biol. 62: 1159-1175.

Fauconneau B., Andre, S., Chmaitilly, J., Le Bail, P.Y., Frieg, F., Kaushik, S.J., 1997.Control of skeletal muscle fibres and adipose cell size in the flesh of rainbow trout. J. Fish Biol. 50: 296-314.

Grisdale-Helland B., HellandS.J., Gatlin,D.M., 2008. The effects of dietary supplementation with mannanoligosaccharide, fructooligosaccharide or galactooligo-saccharide on the growth and feed utilization of Atlantic salmon (Salmo salar). Aquaculture. 283(1): 163-167.

Iwashita Y., Suzuki, N., Matsunari, H., Sugita,T., Yamamoto,T., 2009. Influence of soya saponin, soya lectin, and cholyltaurine supplemented to a casein-based semi purified diet on intestinal morphology and biliary bile status in fingerling rainbow trout Oncorhynchus mykiss. Fish. Sci. 75(5): 1307-1315.

Johnston I.A., Mclay, H.A., Abercromby, M., Robins, D., 2000. Early thermal experience has different effects on growth and muscle fibre recruitment in spring- and autumn-running Atlantic salmon populations. J. Exp. Biol. 203: 2553-2564.

Johnston I.A., Manthri S., Alderson R., Campbell P., Mitchell D., Whyte D., Dingwall A., Nickell D., Selkirk C., Robertson, B., 2002. Effects of dietary protein level on muscle cellularity and flesh quality in Atlantic salmon with particular reference to gaping Aquaculture. 210: 259-283. 
Johnston I.A., Manthri S., Smart A., Campbell P., Nickell D., Alderson, R., 2003. Plasticity of muscle fibre number in seawater stages of Atlantic salmon in response to photoperiod manipulation. J. Exp. Biol. 206: 3425-3435.

Kaushik S.J., Cravedi J.P., Lalles J.P., Sumpter J., Fauconneau B., Laroche, M., 1995.Partial or total replacement of fish meal by soybean protein on growth, protein utilization, potential estrogenic or antigenic effects, cholesterolemia and flesh quality in rainbow trout.Aquaculture.133: 257-274.

Kiessling A., Storebakken T., Asgard T., Kiessling, K.-H., 1991. Changes in the structure andfunction of the epaxial muscle of rainbow trout (Oncorhynchus mykiss) in relation to rationand age-I. Growth dynamics. Aquaculture.93: 335-356.

Knudsen D., UránP., ArnousA., KoppeW., Frøkiær,H., 2007.Saponin-containing subfractions of soybean molasses induce enteritis in the distal intestine of Atlantic salmon. J. Agricul. Food Chem. 55(6): 2261-2267.

Luisa M.P.V., EduardaM.C., Vera S., Luis M.C., Jorge, M.O.F., 2016. Plant protein blends in diets for Senegalese sole affect skeletal muscle growth, flesh texture and the expression of related genes. Aquaculture.453: 77-85.

Refstie S., LandsverkT., Bakke-McKellepA.M.,RingøE.,SundbyA.,Shearer K.D., Krogdahl Å., 2006. Digestive capacity, intestinal morphology, and microflora of 1 year and 2 year old Atlantic cod (Gadus morhua) fed standard or bioprocessed soybean meal. Aquaculture. 261(1):269-284.

Refstie S., StorebakkenT., RoemA.J., 1998. Feed consumption and conversion in Atlantic salmon (Salmo salar) fed diets with fish meal, extracted soybean meal or soybean meal with reduced content of oligosaccharides, trypsin inhibitors, lectins and soya antigens. Aquaculture.162: 301-312.

Rowlerson A., Veggetti A., 2001. Cellular mechanisms of post-embryonic muscle growth in aquaculture species. In: Johnston, I.A. (Ed.), Muscle Development and Growth, Fish Physiology Series, vol. 18. Academic Press, San Diego, pp. 103-140.

Rodehutscord M., Mandel S., Pack M., Jacobs S., Pfeffer, E., 1995. Free amino acids can replace protein-bound amino acids in test diets for studies in rainbow trout (Oncorhynchus mykiss). J. Nutr. 125: 956-963.

Silva P., Valente L.M.P., Galante M.H., Andrade C.A.P., Monteiro R.A.F., Rocha, E., 2009.Dietary protein content influences both growth and size distribution of anterior and posterior muscle fibres in juveniles of Pagellus bogaraveo (Brunnich). J. Muscle Res. Cell Motility. 30: 29-39.

Valente L.M., Cabral E.M., Sousa V., Cunha L.M., Fernandes, J.M., 2016. Plant protein blends in diets for Senegalese sole affect skeletal muscle growth, flesh texture and the expression of related genes. Aquaculture.453, 77-85.

Watanabe T., Verakunpiriya V., Watanabe K., Viswanath K., atoh, S., 1998. Feeding of rainbow trout with non-fish meal diets. Fish. Sci. 63: 258-266.

Weatherley A.H., Gill H.S., Rogers S.C., 1980. Growth dynamics of mosaic muscle fibres in fingerling rainbow trout (Salmo gairdneri) in relation to somatic growth rate. Can. J. Zool. 58: 1535-1541. 